\title{
The Impact of Emotional Labor on Emotional Exhaustion of Academics in State Universities of Sri Lanka
}

\author{
T. J. R. Thisera ${ }^{1}$ and W. B. M. A. P. L. Bandara ${ }^{2}$ \\ ${ }^{1,2}$ Department of Human Resource Management, Faculty of Commerce and \\ Management Studies, University of Keleniya, Sri Lanka \\ 1jeewanthi@kln.ac.lk, ${ }^{2}$ wbmapl@gmail.com \\ (D) https://orcid.org/0000-0002-8755-262X
}

\begin{abstract}
This study examines the impact of emotional labor on emotional exhaustion of academics in state universities in Sri Lanka. The study is quantitative. Data was collected through a standard questionnaire from 221 academics in state universities in Sri Lanka. Regression analysis was used to analyze data. Findings of the study reveals that there is a positive impact of emotional labor on emotional exhaustion while the impact of surface acting on emotional exhaustion is greater than the impact of deep acting on emotional exhaustion. Further, this study has theoretical and practical implications.
\end{abstract}

Keywords: Emotional Labor, Emotional Exhaustion, Work-Family Conflict, Surface Acting, Deep Acting

\section{Introduction}

Teaching is an occupation, which consists of high level of work-related tension (Hakanen, Bakker, \& Schaufeli, 2006). The main responsibility of teaching profession is supporting with the learning activities of students to achieve their educational goals. Literature shows that teaching requires considerable amount of emotional labor (Ogbonna \& Harris, 2004). They further revealed that emotional labor is associated with negative psychological consequences such as stress and emotional exhaustion that cause to emerge burnout among teachers. Lee and Ashforth (1990) have mentioned that emotional exhaustion as the most important demonstration and the central quality of burnout. Hence, emotional labor is a serious problem affecting the psychological and social well-being of service workers (Hoschschild, 1983). Hochschild (1983) further describes two dimensions of emotional labor as deep acting and surface acting. Surface acting means that employees fake to feel the things that they do not feel in reality (Ashforth \& 
Humphrey, 1993). If an individual tries to feel the real emotions that he required to feel because of the rules of behavior, it is defined as deep acting. In deep acting, emotions are actively encouraged, concealed or shaped (Basim \& Begenirbas, 2012).

Empirical evidence (e.g., McDermid, 2010; Milner \& Hoy, 2003) shows that most of the teachers left their jobs because of dissatisfaction and emotional exhaustion. For an example, one fourth of Novice teachers leave their occupation before their third year, and nearly $40 \%$ leave the teaching within the first five years after being qualified in United States (Milner \& Hoy, 2003). According to McDermid (2010), less than one out of ten teachers remain until retirement in Germany. However, when looking at Sri Lanka, there can be seen a limited research attempts (e.g., Hewage \& Fonseka, 2015; Thisera \& Silva, 2016) on emotional labor and emotional exhaustion.

Researchers conducted a pilot survey and discussions in order to verify whether Sri Lankan academics get emotionally exhausted or not. It was conducted using 30 academics. Findings of the pilot survey revealed that majority (78\%) of them get exhausted. Further, discussions conducted with several academics exposed that are vulnerable to exhaustion. With the support of the results of pilot survey, discussions and empirical evidence, the present study examines why academics are emotionally exhausted in state universities in Sri Lanka? In order to answer this research problem, the impact of emotional labor; deep acting and surface acting on emotional exhaustion were tested.

\section{Literature Review}

Emotional exhaustion refers to feelings of being emotionally overextended and depleted of one's emotional resources (Maslach, 1993, p.20, 21). Lee and Ashforth (1990) have mentioned that emotional exhaustion, the feeling of emotionally tired as the most important demonstration and the central quality of burnout. Job dissatisfaction, turnover intention, absenteeism, and physical illnesses are some of the consequences of emotional exhaustion (Youngmi, 2016). The services provided for clients are gradually depreciated by it (Maslach \& Goldberg, 1998). Further, burnout occurs as a reaction to occupational stress in the occupations with human interactions (Maslach, Jackson, \& Leiter, 1996). The feelings that people experience, reflect on, 
interpret, express, and manage are called as emotions (Thoits, 1989; Mills \& Kleinman, 1988 as cited in Chu, 2002). These emotions are influenced by cultural, social, interpersonal and situational conditions and beginning through social interaction (Martin as cited in Chu, 2002). Chu (2002) further mentioned that people experience many suppressing felling in their day to day lives and display such emotions as socially accepted. Regulating one's emotions and complying with social norms is known as emotion work (Hochschild, 1990).

The Conservation of Resources (COR) theory (Hobfoll, 2001) is used to explain how emotional labor contributes to explain the variance in emotional exhaustion in the current study (Noor \& Zainuddin, 2011). This theory examines the collaboration between the person and the environment and the degree of compatibility between demands in the environment and the individual's resources to deal with those demands. The basic principle of COR theory is that almost all the people in the world are struggle to attain, keep, protect and nurture the valuable things that they have. That is individuals are trying to gather and reserve the resources more and more for the better direction of the demands and challenges in their lives. Anything which adds positive value to a person is known as a resource. According to Hobfoll (1988), resources can be divided into two parts as personal and external resources (features of the environment).

Personal values such as importance of achievement, personality traits such as hardiness and internal locus of control and other characteristics including positive affect are known to be as personal resources while the environmental resources are vary depending on the kind of environment that the person works. Importantly, a major environmental resource, which supports to reduce the stress and emotional exhaustion, is the social support from colleagues in the working environment. However, the importance of the COR theory is that it considers the both individual and environmental resources simultaneously and culture defines the extent of values and ranks of these resources. The fundamental idea of the theory is that stressful situations lead to resource losses.

When looking at the emotional labour, Hochschild (1983) has defined EL as the management of feeling to create a publicly observable facial and bodily display; emotional labor is sold for a wage and therefore has exchange value 
(p.7). Moreover, Hochschild (1983) mentioned that surface and deep acting represent two distinct techniques to manage emotion. Moreover, Grandey (2000) explained this concept as the process of regulating both feelings and expressions for organizational goals. Following paragraphs are devoted to discuss the relationship between emotional labor and emotional exhaustion.

\section{Surface Acting and Emotional Exhaustion}

Kinman et al. (as cited in Anomneze, Ugwu, Enwereuzor, \& Ugwu, 2016) has explored the relationship among emotional labor, burnout and job satisfaction among secondary school teachers in United Kingdom. In their study, they found that there is a significant positive association between emotional labor and emotional exhaustion. Moon, Hur, and Jun (2013) found that surface acting is positively associated with emotional exhaustion.

Moreover, there are past studies (e.g., Bono \& Vey, 2005; Grandey, 2003; Karim, 2009; Thisera \& Silva, 2016) which have shown a positive impact of surface acting on emotional exhaustion. Accordingly, hypothesis 1 is set with the support of empirical research and COR theory.

$\mathbf{H}_{\mathbf{1}}$ : There is positive impact of surface acting on emotional exhaustion among academics in state universities in Sri Lanka.

\section{Deep Acting and Emotional Exhaustion}

When looking at empirical studies on deep acting and emotional exhaustion, there can be seen inconsistent findings. For examples some researchers (e.g., Moon et al., 2013; Thisera \& Silva; 2016) found that deep acting was negatively associated with the emotional exhaustion. At the same time, many other studies (e.g., Bono \& Vey, 2005; Grandey, 2003; Karim, 2009) have shown a positive association between deep acting and emotional exhaustion. Noor and Zainuddin (2011) found a positive relationship between emotional labor and emotional exhaustion in their study conducted using female teachers. Accordingly, the next hypothesis is set based on empirical evidence and COR theory.

$\mathbf{H}_{2}$ : $\quad$ There is an impact of deep acting on emotional exhaustion among academics in state universities in Sri Lanka. 


\section{Methodology}

The present study is an explanatory and quantitative study attempted to investigate 'why academics are exhausted? This is a cross sectional study. The unit of analysis is individual. The population of the study was all the academics in state universities in Sri Lanka and used 221 academics from all faculties. Convenience sampling technique was used to collect data while using a self-administered questionnaire. Questionnaire was developed using standard measures available for each variable of emotional labor and emotional exhaustion. Moreover, demographic information was obtained. Data screening was done before testing hypotheses. Then preliminary analysis was done to ensure normality, linearity, validity, reliability, correlation, as well as common method variance. Regression analysis was used to test hypotheses.

\section{Measures}

Emotional labour was measured using the measure developed by Brotheridge and Lee (1998, as cited in Youngmi 2016). This measure includes eight (08) Likert scale questions on a range of five values in order to enhance the quality of the data captured. Further, the concept emotional exhaustion was tested through Maslach Burnout Inventory (Maslach, 1981). It consisted with nine questions (09) with seven point Likert scales ranging from never to always. Apart from the above mentioned validated measures, demographic information of respondent such as gender, age, marital status, years of teaching experience, the current designation and the highest educational qualification were asked.

\section{Sample Composition}

The data were gathered from all state universities listed under university Grant Commission. The sample consisted with 55\% of females and $45 \%$ of male academics. Majority of the sample (44\%) belonged to the age group of between 25 to 35 years old academics. Further, the sample comprised 40\% (Majority) of lecturers. 32\% of them was lecturer (probationary) and there was only $3 \%$ of professors from the sample. Senior lecturers were only $25 \%$. 


\section{Data Analysis}

\subsection{Hypotheses Testing}

Researchers tested the direct impact of emotional labor on emotional exhaustion by using the simple regression analysis.

\subsection{Direct Effect}

H1: There is positive impact of surface acting on emotional exhaustion among academics.

Regression analysis was carried out to find the variance of dependent variable from the explanation of independent variable. According to the table $01, \mathrm{R}$ Square value is .424 with sig value 0.000 . Beta value is 0.28 and it is positive. Therefore; it reveals that there is a significant positive impact of surface acting on emotional exhaustion. Accordingly, the $\mathrm{H}_{1}$ is supported.

Table 01: Results of the Regression Analysis

\begin{tabular}{lllll}
\hline \multicolumn{1}{c}{ Construct } & \multicolumn{1}{c}{ R Value } & R Square & Beta Value & Sig Value \\
\hline Surface Acting & 0.651 & 0.424 & 0.28 & 0.000 \\
Deep Acting & 0.743 & 0.552 & 0.31 & 0.000 \\
\hline
\end{tabular}

Source: Survey Data

H2: There is an impact of deep acting on emotional exhaustion among academics.

According to the table 01, R Square value is .552 with the significant value of 0.000 . The beta value is 0.31 . It reveals that there is a significant, positive impact of deep acting on emotional exhaustion. Accordingly, the above mentioned $\mathrm{H} 2$ is supported.

\section{Discussion}

As per the findings of the study there is an impact of emotional labor on emotional exhaustion among academics. Moreover, present survey data reveals that $42 \%$ of impact of surface acting on emotional exhaustion among academics. Since it is a positive impact, when surface acting increases, that causes to increase the exhaustion of 
academics while consistent with previous studies (Bono \& Vey, 2005; Grandey, 2003; Karim, 2009; Thisera \& Silva, 2016)

Moreover, Deep acting positively influenced over emotional exhaustion. The variation of the emotional exhaustion is explained by $55 \%$ by the deep acting. There can be seen inconsistent finding on the impact of deep acting towards emotional exhaustion. These findings are consistent with precious studies (Bono \& Vey, 2005; Grandey, 2003; Karim, 2009).

\section{Limitations}

There can be seen few limitations of the present study. Though the data was collected using convenience sampling, the study used a representative sample of all state universities in Sri Lanka. Further, the study used only single method of data collection, the questionnaire method was used to collect data for the present study. However, apart from the questionnaire method, structured observations and structured interviews with standardized questions can also be used under the survey strategy. Moreover, the present study focuses the impact of emotional labor only on the emotional exhaustion. There are another two dimensions in the burnout syndrome apart from emotional exhaustion that should be taken in to consideration.

\section{References}

Anomneze, E. A., Ugwu, D. I., Enwereuzor, I. K., \& Ugwu, L. I. (2016). Teachers' Emotional Labour and Burnout: Does Perceived Organizational Support Matter? Asian Social Science, 12(2), 9.

Ashforth, B. E., \& Humphrey, R. H. (1993). Emotional labor in service roles: The influence of identity. Academy of Management Review, 18(1), 88-115.

Basim, H. N., \& Begenirbas, M. (2012). ÇalışmaYaşamında Duygusal Emek:

Birolcek Uyarlama Calışmas; Yonetimve Ekonomi: Celal Bayar

Universitesiy ktisadiveldari Bilimler Facultesi Dergisi, 19(1), 77-90.

Chu, K.H.L. (2002). The effects of emotional labor on employee work outcomes (Doctoral Dissertation, Virginia Polytechnic Institute and State University). 
De Silva, P. V., Hewage, C. G., \& Fonseka, P. (2015). Prevalence of burnout and its correlates among female primary school teachers in the southern province of Sri Lanka. European Journal of Preventive Medicine, 3(2-1), 9-14. doi: 10.11648/j.ejpm.s.2015030201.13

Grandey, A. A. (2000). Emotional regulation in the workplace : A new way to conceptualize emotional labour. Journal of Occupational Health Psychology, 5(1), 95-100. doi:10.1037//1076-8998.5.1.95.

Grandey, A. A. (2003). When "the show must go on": Surface acting and deep acting as determinants of emotional exhaustion and peer-rated service delivery. Academy of Management Journal, 46(1), 86-96.

Hakanen, J. J., Bakker, A. B., \& Schaufeli, W. B. (2006).Burnout and work engagement among teachers. Journal of School Psychology, 43(6), 495-513.

Hobfoll, S. E. (2001). The influence of culture, community, and the nested-self in the stress process: advancing conservation of resources theory. Applied Psychology, 50(3), 337-421.

Karim, J. (2009). Emotional labor and psychological distress: Testing the mediatory role of work-family conflict. European Journal of Social Sciences, 11, 584 598

Lee, R. T., \& Ashforth, B. E. (1990). On the meaning of Maslach's three dimensions of burnout. Journal of Applied Psychology, 75(6), 743.

Maslach, C., \& Goldberg, J. (1999). Prevention of burnout: New perspectives. Applied and Preventive Psychology, 7(1), 63-74.

Maslach, C., \& Jackson, S. E. (1981). The measurement of experienced burnout. Journal of Organizational Behavior, 2(2), 99-113.

Maslach, C., Jackson, S. E., \& Leiter, M. P. (1996). Maslach burnout inventory manual. Mountain View, CA: CPP. Inc., and Davies-Black.

Mills, T., \&Kleinman, S. (1988). Emotions, Reflexivity, and Action: An Interactionist Analysis'. Social Forces, 66(4), 1009-1027.

Milner, H. R., \& Hoy, A. W. (2003). A case study of an African American teacher's self-efficacy, stereotype threat, and persistence. Teaching and Teacher Education, 19(2), 263-276. 
Moon, T. W., Hur, W. M., \& Jun, J. K. (2013). The role of perceived organizational support on emotional labor in the airline industry. International Journal of Contemporary Hospitality Management, 25(1), 105-123. http://dx.doi.org/10.1108/09596111311290246

Noor, N. M., \& Zainuddin, M. (2011). Emotional labor and burnout among female teachers: Work-family conflict as mediator. Asian Journal of Social Psychology, 14(4), 283-293.

Ogbonna, E., \& Harris, L. C. (2004). Work intensification and emotional labour among UK university lecturers: An exploratory study. Organization Studies, 25(7), 1185-1203.

Thisera, T. J. R., \& Silva, D. P.A. K. H. (2016). The impact of emotional labour on emotional exhaustion of female nurses in Sri Lanka. International MultiConferences (74-80). Kuala Lumpur, Malaysia: Innovative Research Publication.

Thoits, P. A. (1989). The sociology of emotions. Annual Review of Sociology, 317342. 